\title{
SÃO GABRIEL CIDADE EDUCADORA: PRIMEIROS PASSOS
}

\author{
SAO GABRIEL EDUCATIONAL CITY: FIRST STEPS \\ CIUDAD EDUCATIVA DE SAO GABRIEL: PRIMEROS PASOS
}

\author{
Eduardo Pastorio ${ }^{1}$ \\ Lia Heberlê de Almeida Pastorio² \\ Jaqueline Moll3
}

\begin{abstract}
RESUMO
Este artigo tem como objetivo apresentar o ingresso do município de São Gabriel/RS/Brasil a Associação Internacional de Cidades Educadoras (AICE), com ênfase na descrição dos requisitos exigidos, apresentação da justificativa de habilitação e as novas ações planejadas para a materialização do conceito de Cidade Educadora. A iniciativa ocorreu em agosto de 2019, através da Secretaria Municipal de Educação (SEME), que aprofundou teoricamente o conceito, contatou pesquisadores da área, cumpriu os requisitos (criação da Lei Municipal de Cidades Educadoras, preenchimento do Termo de Adesão solicitando admissão, aceite dos princípios da Carta das Cidades Educadoras e pagamento da Quota Anual 2020) e recebeu o título de Cidade Educadora, em 11 de março de 2020 , tornando-se a $9^{\circ}$ no RS, $21^{\circ}$ no Brasil e a $505^{\circ}$ cidade no mundo. Para a consolidação, três aspectos foram considerados: 1 - responsabilidade e investimento do governo local na educação; 2 - bases históricas e culturais, com bens materiais e imateriais; 3 - atividades e eventos executados em âmbito local, pelos diferentes atores sociais. Em continuidade ao processo inicial, o conceito está sendo adicionado ao currículo escolar e apresentado/aproximado aos diferentes atores sociais locais.
\end{abstract}

PALAVRAS-CHAVES: Cidade Educadora. Associação Internacional de Cidades Educadoras (AICE). São Gabriel/RS. Currículo Escolar.

\footnotetext{
1 Doutorado em andamento em Educação em Ciências pela Universidade Federal do Rio Grande do Sul (UFRGS). Graduado em Licenciatura Plena em Geografia (2012), Especialista em Gestão Educacional (2019) e Mestre em Geografia (2015) pela Universidade Federal de Santa Maria (UFSM). Docente da rede pública estadual do Rio Grande do Sul e da rede pública municipal de São Gabriel/RS. Diretor Administrativo na Secretaria Municipal de Educação de São Gabriel/RS. GPEEC Natureza (UFRGS). E-mail: eduardopastorio@hotmail.com.

2 Mestra e doutoranda em Educação em Ciências pela Universidade Federal do Rio Grande do Sul (UFRGS). Graduada em Licenciatura Plena em Pedagogia (2010) pela Universidade da Região da Campanha (URCAMP). Especialista em Tecnologias da Informação e da Comunicação Aplicadas à Educação (2012) e em Mídias na Educação (2015) pela Universidade Federal de Santa Maria (UFSM). Docente da rede pública municipal de São Gabriel/RS. GPEEC Natureza (UFRGS). E-mail: lia_ha@hotmail.com.

${ }^{3}$ Graduada em Pedagogia pelo Centro de Ensino Superior de Erechim. Especialista em Alfabetização pela Pontifícia Universidade Católica do Rio Grande do Sul (PUC/RS) e em Educação Popular pela Universidade do Vale do Rio dos Sinos (UNISINOS). Mestra em Educação pela Pontifícia Universidade Católica do Rio Grande do Sul (PUC/RS) e Doutorado em Educação pela Universidade Federal do Rio Grande do Sul (UFRGS). Professora-orientadora no Programa de Pós-Graduação de Educação em Ciências: química da vida e saúde da UFRGS e Professora do Programa de Pós-Graduação em Educação da Universidade Regional Integrada do Alto Uruguai e das Missões. Professora Titular da Faculdade de Educação da UFRGS. E-mail: jaquelinemoll@gmail.com.
}

Revista de Ciências Humanas, Frederico Westphalen - RS, v. 22, n.1, p. 59-74, jan./abr. 2021. Recebido em: 23/05/2021 Aceito em: 02/06/2021 


\begin{abstract}
This article aims to present the entry of the municipality of São Gabriel/RS/Brazil to the International Association of Educating Cities (AICE), with emphasis on the description of the requirements, presentation of the justification for qualification and the new actions planned for the materialization of the Educating City concept. The initiative took place in August 2019, through the Municipal Department of Education (SEME), which theoretically deepened the concept, contacted researchers in the area, fulfilled the requirements (creation of the Municipal Law of Educating Cities, filling out the Adhesion Term requesting admission, acceptance of the principles of the Charter of Educating Cities and payment of the 2020 Annual Quota) and received the title of Educating City, on March 11, 2020 , becoming the 9th in RS, 21st in Brazil and the 505th city in the world. For consolidation, three aspects were considered: 1 - responsibility and investment of the local government in education; 2 - historical and cultural bases, with material and immaterial assets; 3 - activities and events carried out at the local level, by different social actors. Continuing the initial process, the concept is being added to the school curriculum and presented/approached to different local social actors.
\end{abstract}

KEYWORDS: Educating City. International Association of Educating Cities (AICE). São Gabriel/RS. School curriculum.

\title{
RESUMEN
}

Este artículo tiene como objetivo presentar el ingreso del municipio de São Gabriel / RS / Brasil a la Asociación Internacional de Ciudades Educadoras (AICE), con énfasis en la descripción de los requisitos, presentación de la justificación de la calificación y las nuevas acciones previstas. para la materialización del concepto de Ciudad Educadora. La iniciativa se llevó a cabo en agosto de 2019, a través de la Secretaría Municipal de Educación (SEME), que teóricamente profundizó el concepto, contactó a investigadores de la zona, cumplió con los requisitos (creación de la Ley Municipal de Ciudades Educadoras, cumplimentación del Plazo de Adhesión solicitando admisión, aceptación de los principios de la Carta de Ciudades Educadoras y pago de la Cuota Anual 2020) y recibió el título de Ciudad Educadora, el 11 de marzo de 2020, convirtiéndose en la novena en RS, 21 en Brasil y 505 en el mundo. Para la consolidación se consideraron tres aspectos: 1 - responsabilidad e inversión del gobierno local en educación; 2 - bases históricas y culturales, con bienes materiales e inmateriales; 3 - actividades y eventos realizados a nivel local, por diferentes actores sociales. Continuando con el proceso inicial, el concepto se agrega al currículo escolar y se presenta / aborda a diferentes actores sociales locales.

PALABRAS CLAVE: Ciudad Educadora. Asociación Internacional de Ciudades Educadoras (AICE). São Gabriel I RS. Currículum escolar.

\section{INTRODUÇÃO}

No Brasil, a educação é "direito de todos e dever do Estado e da família", como preconiza a Constituição Federal do Brasil de 1988, reforçando que "será promovida e incentivada com a colaboração da sociedade, visando ao pleno desenvolvimento da pessoa, seu preparo para o exercício da cidadania e sua qualificação para o trabalho".

A educação tem o papel fundamental na construção das sociedades contemporâneas, capazes de formar atores sociais ativos e participativos em seus lócus. $O$ processo formativo do indivíduo ocorre ao longo da vida, em todos tempos e espaços, de forma contínua e progressiva, que "a educação ao longo da vida contribui para este bem-estar na medida em que para além de favorecer o crescimento 
pessoal, permite reduzir as desigualdades ou diferenças significativas entre pessoas, grupos, bairros... de uma mesma cidade" (AICE, 2019).

O exposto, sintetiza que a educação está presente em todos os momentos das pessoas e colabora com a expressão "cidade educativa" ou "cidade educadora", citada no Relatório da UNESCO em 1973, elaborado por Edgar Faure com o nome de Aprender a Ser, ao afirmar:

\footnotetext{
Se aprender é ação de toda uma vida, tanto na sua duração como na sua diversidade, assim como de toda uma sociedade, no que concerne quer às suas fontes educativas, quer às sociais e econômicas, então, é preciso ir ainda mais além na revisão necessária dos sistemas educativos e pensar na criação duma sociedade educativa. Esta é a verdadeira dimensão do desafio educativo do futuro (FAURE, 1973)
}

O conceito citado no Relatório da UNESCO é retomado por um grupo de governos locais no final da década de 80 , preocupados em pensar de forma coletiva os problemas e o papel das cidades, com ênfase as funções educativas, que se materializou na realização do $1^{\circ}$ Congresso Internacional das Cidades Educadoras (Barcelona/Espanha), com a presença de 60 cidades, de 21 países do mundo.

O congresso permitiu a criação da Associação Internacional de Cidades Educadoras, fundada em 1994, que é "constituída como uma estrutura permanente de colaboração entre governos locais que se comprometem a reger-se pelos princípios inscritos na Carta das Cidades Educadoras", em que qualquer governo local pode ingressar a entidade, desde que cumpra com os requisitos iniciais.

Em 2020, a AICE perpassou o número de 500 Cidades Educadoras associadas, de 34 países do mundo, contando com a presença de São Gabriel/RS. Nesse sentido, que este artigo tem como objetivo apresentar o ingresso do município de São Gabriel/RS/Brasil a Associação Internacional de Cidades Educadoras (AICE), com ênfase na descrição dos requisitos exigidos, apresentação da justificativa que habilita a unidade territorial e as novas ações planejadas para a materialização do conceito de Cidade Educadora (AICE,2020).

A unidade territorial iniciou os trâmites em agosto de 2019, através de iniciativa da Secretaria Municipal de Educação (SEME), que aprofundou teoricamente o conceito e contatou pesquisadores da área. Após, cumpriu os requisitos exigidos (criação da Lei Municipal de Cidades Educadoras, preenchimento do Termo de Adesão solicitando admissão, aceite dos princípios da Carta das Cidades Educadoras e pagamento da Quota Anual 2020) e recebeu o título de Cidade Educadora, em 11 de março de 2020 , tornando-se a $9^{\circ}$ no $\mathrm{RS}, 21^{\circ}$ no Brasil e a $505^{\circ}$ cidade no mundo.

Revista de Ciências Humanas, Frederico Westphalen - RS, v. 22, n.1, p. 59-74, jan./abr. 2021. Recebido em: 23/05/2021 
Para a consolidação, três importantes aspectos foram considerados: 1 - responsabilidade e investimento do governo local na educação; 2 - bases históricas e culturais, com bens materiais e imateriais; e, 3 - atividades e eventos executados em âmbito local, pelos diferentes atores sociais. Em continuidade ao processo inicial, o conceito está sendo adicionado ao currículo escolar e apresentado/aproximado aos diferentes atores sociais locais.

\section{CIDADE EDUCADORA: PREMISSAS TEÓRICAS E PROCEDIMENTOS DE INGRESSO}

Pensar o conceito de Cidade Educadora propicia retomar os preceitos da definição de "cidade", enquanto território de reprodução das relações sociais e de "educação", como processo e ação contínuo para o desenvolvimento de habilidade e capacidades intelectuais e morais das pessoas, em diferentes níveis e idade.

$\mathrm{Na}$ origem etimológica da palavra cidade, encontra-se dois termos no latim: "civitas", que também está na base da construção das palavras de cidadão e civilização; e "urbs", que contribuiu na formulação da palavra urbano (LACOSTE, 2005). Apesar das proximidades dos termos de cidade e urbano em sua origem, bem como no imaginário das pessoas, teóricos diferenciam, como o geógrafo brasileiro Milton Santos (1994), ao se referir o urbano como "o abstrato, o geral e o externo" e cidade como "o particular, o concreto e o interno".

Mesmo assim, Santos (1994) reforça que cidade seria, ao mesmo tempo, uma região e um lugar, ou seja, território em que os atores sociais expressam as suas relações, em uma construção contínua e dinâmica. Nesse sentido que o Geógrafo David Harvey (1973) define o termo cidade como um "[...] sistema dinâmico complexo no qual a forma espacial e o processo social estão em contínua interação" e demonstra as múltiplas definições do termo, fazendo com que Cavalcanti (2012) mencione que, mesmo se tratando de conceitos distintos, não podem ser considerados de forma isoladas, sendo a cidade o visível do urbano.

No termo educação, remeto ao disposto no Artigo $1^{\circ}$ da LDB, que "abrange os processos formativos que se desenvolvem na vida familiar, na convivência humana, no trabalho, nas instituições de ensino e pesquisa, nos movimentos sociais e organizações da sociedade civil e nas manifestações culturais". Apesar da legislação citada nortear a educação escolar brasileira, consegue direcionar as múltiplas dimensões e atores que envolvem a construção da educação, como destaca Freire (2003), que "ninguém educa ninguém, como tão pouco ninguém se educa a si mesmo: os homens se educam

Revista de Ciências Humanas, Frederico Westphalen - RS, v. 22, n.1, p. 59-74, jan./abr. 2021. Recebido em: 23/05/2021 
em comunhão, mediatizados pelo mundo". Nesse sentido que uma cidade é naturalmente educadora e que, ao mesmo tempo, "enquanto educadora a cidade é também educanda" (FREIRE, 1993).

Quando pensamos a Cidade Educadora, estamos falando de cidades "que assumam a responsabilidade de fazer da cidade um âmbito de formação cidadã, individual e coletivo, e a preocupação por comprometer todos os atores [...] nesta tarefa" (AICE AMÉRICA LATINA, 2019). Na Carta das Cidades Educadoras da Declaração de Barcelona (1990), na tentativa de definir Cidade Educadora, destaca que,

A cidade será educadora quando reconheça, exerça e desenvolva, para além das suas funções tradicionais (económica, social, política e de prestação de serviços), uma função educadora, isto é, quando assuma uma intencionalidade e responsabilidade, cujo objectivo seja a formação, promoção e desenvolvimento de todos os seus habitantes, a começar pelas crianças e pelos jovens (AICE, 1994).

A Cidade Educadora, pensada para todos os seus habitantes, constituem para além dos espaços educativos escolares, é quando o ensinar e o aprender ganham novos significados e desafios, como destacado na Carta das Cidades Educadoras:

As cidades educadoras, com suas instituições educativas formais, suas intervenções não formais (de uma intencionalidade educadora para além da educação formal) e informais (não intencionais ou planificadas), deverão colaborar, bilateral ou multilateralmente, tornando realidade a troca de experiências (AICE, 2004).

A relação indissociável dos termos de cidade e educação ocorre, pois apesar dos inúmeros objetivos cabe "[...] à educação a responsabilidade de abrir as portas da mente e do coração e de apontar horizontes de construção partilhada de sociedades humanas mais humanizadas" (BRANDÃO, 2002), partindo do princípio da construção de uma educação como processo de humanização (FREIRE, 1994), frente as demandas sociais encontradas.

Arroyo (2001), destaca os princípios defendidos por Paulo Freire, que:

[...] educar sempre será uma relação de gente com gente, de adultos com crianças. [...] Para Paulo Freire, o caráter renovador da educação está no caráter intrinsicamente renovado de toda a relação humana, entre humanos. Formamo-nos no diálogo, na interação com outros humanos, não nos formamos na relação com o conhecimento. Este pode ser mediador dessa relação como pode também suplantar essa relação.

Pensar uma cidade educadora é transformar as cidades em território de aprendizagens mútuas entre as pessoas, em lugar de potencial educativo, de pensar coletivamente os problemas e o papel 
educador das cidades. Baseado nessas inspirações, que o conceito de Cidade Educadora ganha ênfase na realização do $1^{\circ}$ Congresso Internacional das Cidades Educadoras, em Barcelona/Espanha, no ano de 1990, com a participação de representantes de 21 países.

$\mathrm{Na}$ oportunidade foi elaborada a Carta Inicial, que definiu os princípios básicos para reger 0 impulso educador da cidade. O documento criado em 1990, foi reavaliado em Gotemburgo/Suécia (1992) e aprovada Bolonha (1994), com criação do documento intitulado de Carta das Cidades Educadoras, sendo novamente reavaliada em Génova/ltália (2004). As avaliações são importantes para realizar ajustes no documento, diante aos novos desafios diários das cidades, com o objetivo de promover as cidades mais inclusivas, mais justas e mais participativas. Em 2020, haveria a comemoração dos 30 anos das Cidades Educadoras, na realização do XVI Congresso Internacional, que ocorreria em Katowice/Polônia, porém o evento foi cancelado devido a pandemia do Coronavírus.

A carta é a síntese das aspirações dos membros da AICE e quando uma cidade opta em ingressar a associação, precisa aderi-la e assumir o seu compromisso de forma integral. Segundo a Carta das Cidades Educadoras (2020) e o Estatuto da Associação Internacional das Cidades Educadoras, os membros devem seguir os seguintes objetivos:

a) Proclamar e reivindicar a importância da educação na cidade.

b) Evidenciar as vertentes educativas dos projetos políticos das cidades associadas.

c) Promover, inspirar, fomentar e acompanhar o cumprimento da Carta das Cidades Educadoras (Declaração de Barcelona) nas cidades-membro, bem como assessorar e informar os seus membros relativamente ao fomento e à implantação dos mesmos.

d) Representar os associados na execução dos fins associativos, estabelecendo contactos e colaborando com organizações internacionais, estados, entidades territoriais de todo o tipo, sendo a AICE um interlocutor válido e significativo nos processos de influência, negociação, decisão e redação.

e) Criar laços e colaborar com outras associações, federações, agrupamentos ou Redes Territoriais, especialmente de cidades, em esferas de ação similares, complementares ou concorrentes.

f) Cooperar em todos os âmbitos territoriais que se enquadrem nos fins da presente Associação.

g) Promover o aprofundamento do conceito de Cidade Educadora e as suas aplicações práticas nas políticas das cidades, através de intercâmbios, encontros, projetos comuns, congressos, atividades e iniciativas que reforcem os laços entre as cidades associadas, no âmbito das delegações, Redes Territoriais, Redes Temáticas e outros agrupamentos.

Quando a cidade conseguir compreender e guiar por estes objetivos, iniciará a caminhada como Cidade Educadora, pois irá reconhecer, promover, exercer e praticar uma função educadora na vida das pessoas. Quando os diferentes espaços, tempos e atores serem compreendidos como agentes sociais, capazes de apoiar o desenvolvimento do potencial humano, contribuirá na construção

Revista de Ciências Humanas, Frederico Westphalen - RS, v. 22, n.1, p. 59-74, jan./abr. 2021. Recebido em: 23/05/2021 Aceito em: 02/06/2021 
permanente e contínua da formação integral de crianças, jovens, adultos e idosos, formando o Território Educativo (ACEA, 2018).

Cidade, que para Tascheto (2019) "reproduz materialmente as contradições da própria sociedade, ao mesmo tempo que produz essas contradições socialmente" e que nesse sentido, poderia pensar a cidade como "usina de aprendizagem", que "significa pensar o que queremos de nós mesmos, a cidade que queremos está colada na ideia do tipo de homem e mulher que queremos ser" (TASCHETTO, 2019).

$\mathrm{Na}$ construção dos Territórios Educativos é essencial "o avanço da democracia e o aprofundamento das formas de participação social" e que a "partir de políticas públicas e ações que estimulam o vínculo e o reconhecimento das populações com o território, um território que educa, deve assegurar a todos 0 acesso aos bens culturais produzidos em uma determinada localidade" (ACEA, 2018).

Em síntese, diante aos desafios contemporâneos, as construções de Territórios Educativos buscam o desenvolvimento social, cultural e econômico local, seguindo princípios concretos, "enfrentando os problemas urbanos de forma sistêmica, transparente e horizontal" e "remete a uma concepção abrangente de educação, em que o processo educativo confunde-se com um processo amplo e multiforme de socialização" (ACEA, 2018).

Todo território caminha para a materialização como Cidade Educadora, quando preencher os preceitos teóricos apresentados. Porém, para tornar-se Cidade Educadora na Associação Internacional, necessita cumprir os requisitos estabelecidos pela entidade, que deve cumprir a seguinte sequência: criar a Lei Municipal sobre Cidades Educadoras; preencher o formulário de adesão na AICE; assumir a Carta das Cidades Educadoras; e, pagar a taxa/quota anual. No cumprimento dos procedimentos (também disponível no site), os documentos devem ser unificados e enviados para 0 Secretariado da AICE, para análise e aprovação.

\section{CARACTERIZANDO O MUNICÍPIO DE SÃO GABRIEL (RIO GRANDE DO SUL/BRASIL)}

A unidade territorial de São Gabriel foi fundada em 04 de abril de 1846 e é um município brasileiro localizado no interior do estado do Rio Grande do Sul (RS) (320 km da capital Porto Alegre), pertencente a Microrregião da Campanha Central e inserido na Mesorregião Sudoeste Rio-Grandense, próximo da fronteira com o Uruguai $(170 \mathrm{~km})$ e Argentina (320 km) (Figura 1). Em relação aos 497 municípios do estado Rio Grande do Sul, São Gabriel é a $37^{\circ}$ maior em população (62.105 habitantes) 
e $6^{\circ}$ maior em área territorial $\left(5020 \mathrm{~km}^{2}\right)$. No contexto econômico, as atividades (nos três setores primária, secundária e terciária) são vinculadas ao setor agropecuário (agricultura e pecuária).
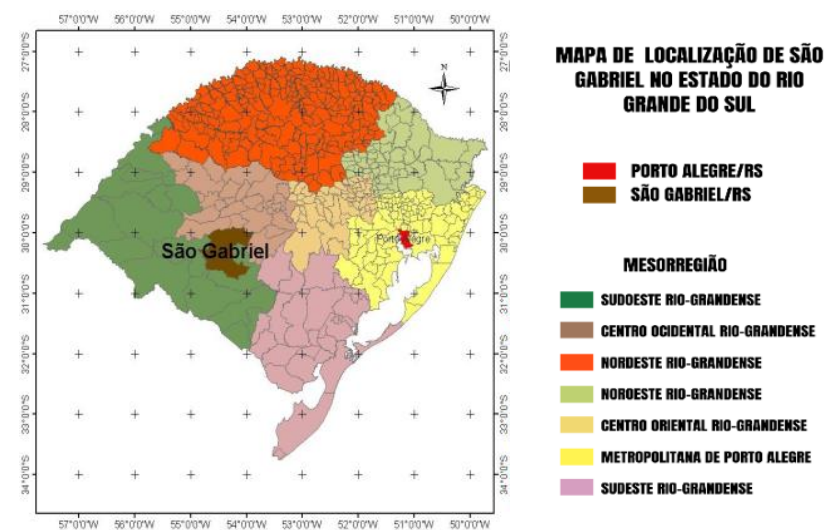

Figura 1 - Mapa de localização de São Gabriel na Mesorregião Sudoeste do Rio Grande do Sul/Brasil Fonte: PASTORIO, 2015.

O território "gabrielense" (gentílico pátrio atribuído a comunidade, residentes ou nascidos) foi lugar de momentos importantes da história do Rio Grande do Sul e do Brasil, sendo sede do governo da República Riograndense (em 1840, durante a Revolução Farroupilha), recebeu a visita do Dom Pedro II (em 1846 e 1865), palco de grandes batalhas (Batalha do Caiboaté, em 1756, e do Cerro do Ouro, em 1893) e ligação direta com as demarcações de terra (Tratado de Madrid, de 1750, e Tratado de Santo Idelfonso, de 1777). Sua formação cultural está vinculada aos espanhóis, portugueses e indígenas, e atualmente carrega os títulos de "Terra dos Marechais", "Princesa das Coxilhas", "Atenas Rio-Grandense" e "Último Reduto dos Carreteiros".

\section{CONSTRUINDO SÃO GABRIEL COMO CIDADE EDUCADORA}

O município de São Gabriel/RS/Brasil iniciou sua trajetória nas Cidades Educadoras, em 29 e 30 de agosto de 2019, quando a Secretaria Municipal de Educação enviou representante ao evento intitulado II Encontro sobre Cidades Educadoras e Inteligentes: construindo territórios educativos, no município de Soledade/RS, organizado pela Universidade de Passo Fundo e pela Secretaria Municipal de Educação de Soledade/RS e Marau/RS.

O evento científico teve como objetivo ampliar o debate teórico metodológico de Cidades Educadoras e Inteligentes estabelecendo relações entre o regional e o global na perspectiva do desenvolvimento urbano e social dos territórios, e estava direcionado para diferentes públicos-alvo,

Revista de Ciências Humanas, Frederico Westphalen - RS, v. 22, n.1, p. 59-74, jan./abr. 2021. Recebido em: 23/05/2021 Aceito em: 02/06/2021 
com destaque aos gestores públicos. Contou coma presença de grandes lideranças do tema como Profa. Dra. Jaqueline Moll (UFRGS), Prof. Dr. Márcio Tascheto (UPF/UFN), Prof. Ramires Brilhante (Rede Brasileira de Cidades Educadoras), Prof. Me. Carlos Fress (Vice-presidente da Rede Brasileira de Cidades Inteligentes e Humanas) e Laura Alfonso (Diretora da Delegação para América Latina da AICE), além de representantes e trocas de experiências das cidades de Carazinho/RS, Camargo/RS, Santiago/RS, Soledade/RS, Marau/RS, Vitória/ES e Rosário/Argentina.

O mês de setembro serviu para apresentar a proposta aos colaboradores da gestão da Secretaria Municipal de Educação, elaborar documento que justifique o ingresso de São Gabriel na AICE, compreender os passos e iniciar os trâmites. A proposta foi apresentada ao Prefeito Municipal, no dia 15 de outubro, que compreendeu a importância do conceito e destacou que Cidade Educadora poderá contribuir na construção de uma cidade mais coletiva e participativa.

No dia 16 de outubro de 2019, a Secretaria Municipal de Educação encaminhou o Memorando $\mathrm{N}^{\circ}$ 257, para a Secretaria Municipal de Administração, com o seguinte requerimento: "vimos através deste solicitar a criação da Lei de Cidade Educadora, que dispõe sobre a autorização para a adesão do município de São Gabriel/RS à Carta das Cidades Educadoras e ingresso na Associação Internacional de Cidades Educadoras - AICE", que constava em anexo o esboço do Projeto de Lei e a Justificativa de Ingresso.

A documentação foi encaminhada pelo Poder Executivo à Câmara de Vereadores, através do Projeto de Lei $\mathrm{N}^{\circ}$ 0090, de 12 de novembro de 2019, com apreciação e aprovação por unanimidade em plenária no dia 28 de novembro, sendo estabelecida oficialmente como Lei Municipal № 4067, de 16 de dezembro de 2019, que "Dispõe sobre a autorização para a adesão à Carta das Cidades Educadoras e ingresso na Associação Internacional das Cidades Educadoras - AICE, e dá outras providências".

Com o cumprimento do primeiro passo, encaminhamos (via e-mail) a Lei Municipal para a Delegação para a América Latina da AICE, que solicitou o preenchimento e assinatura do Formulário de Adesão pelo Prefeito Municipal (chefe do Poder Executivo), mais o representante técnico e representante político do governo municipal, que assumem a Carta das Cidades Educadoras e solicitam a admissão na AICE.

O formulário foi finalizado no dia 31 de janeiro de 2020 e encaminhado (via e-mail) no dia 03 de fevereiro para a Delegação para a América Latina, que unificando com a Lei Municipal, encaminharam na mesma data o Secretariado da AICE (Barcelona/Espanha). No dia 05 de fevereiro recebemos, do Secretariado da AICE, o boleto para pagamento da quota/taxa anual, seguindo a tabela das quotas anuais 2019 da AICE.

Revista de Ciências Humanas, Frederico Westphalen - RS, v. 22, n.1, p. 59-74, jan./abr. 2021. Recebido em: 23/05/2021 Aceito em: 02/06/2021 
Houve dificuldades para o pagamento da quota, em virtude de se tratar de um boleto de outro país, em que o banco cobrou pagamento de taxa extra para efetivação da transação bancária. Recebemos a confirmação do pagamento pelo banco no dia 10 de março de 2020, sendo que na mesma data foi encaminhado para a AICE, com cópia para a Delegação para a América Latina, com aprovação de ambos setores.

No dia 11 de março de 2020, recebemos a confirmação do ingresso do município de São Gabriel/RS na AICE, recebendo o título de Cidade Educadora, tornando-se a $9^{\circ}$ no $\mathrm{RS}, 21^{\circ}$ no Brasil e a $505^{\circ}$ no mundo, entre 34 países (sendo 9 países da América), com a maioria das cidades e países participantes serem europeus. Salienta-se que, de março a junho de 2020, houve o ingresso de mais 2 cidades a AICE (Figura 2).

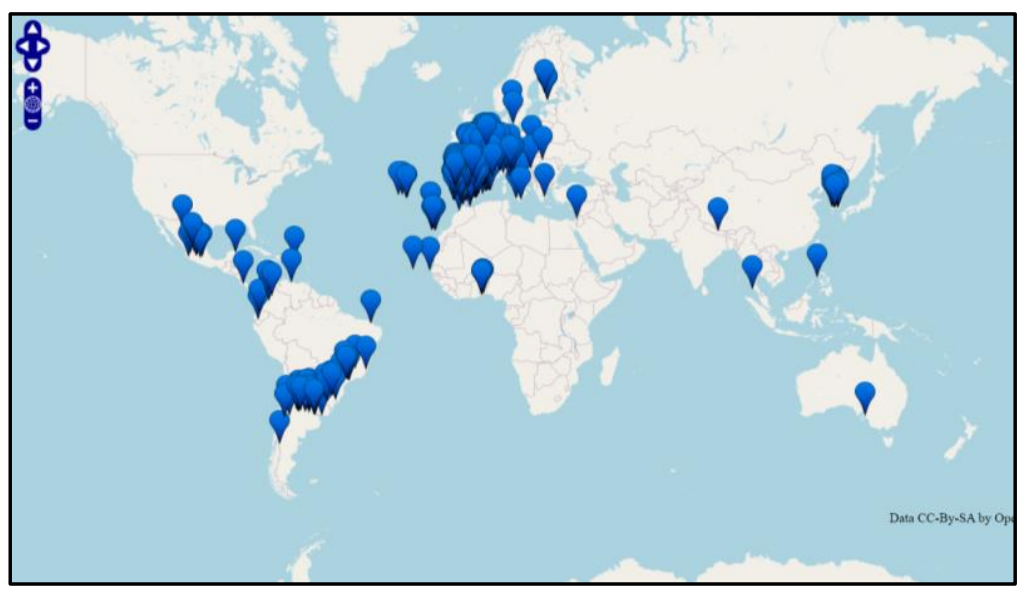

Figura 2 - Mapa das Cidades Educadoras do Mundo Fonte: AICE, 2020.

As cidades brasileiras membros da AICE são: Belo Horizonte, Camargo, Carazinho, Caxias do Sul, Curitiba, Guarulhos, Horizonte, Marau, Mauá, Nova Petrópolis, Porto Alegre, Santiago, Santo André, Santos, São Bernardo do Campo, São Carlos, São Gabriel, São Paulo, Soledade, Sorocaba e Vitória (os nomes grifados referem-se cidades do Rio Grande do Sul, que estão representados na Figura 3).

Houve atraso na divulgação para a comunidade do recebimento do título de Cidade Educadora, em virtude da pandemia do coronavírus (COVID-19), que estava em avanço progressivo no início de março, que acarretou a suspensão das aulas presenciais e todos os focos do governo local foram para prevenção e controle da pandemia. Diante a continuação e sempre previsão de retorno da normalidade, a divulgação ocorreu por meio eletrônico, através dos canais oficiais de comunicação da 
Prefeitura Municipal e da Secretaria Municipal de Educação de São Gabriel/RS, como também pela impressa local e regional, no dia 22 de maio de 2020.

Apesar do adiamento da divulgação, os representantes de São Gabriel Cidade Educadora estão participando das atividades desenvolvidas pela Delegação para a América Latina da AICE como o Curso "Construção de uma Cidade Educadora" e o Curso "Infância e o Papel Educador das Cidades". Também ocorreu a participação na Reunião Virtual da Rede Brasileira de Cidades Educadoras (REBRACE), ingressando oficialmente a rede e das discussões em nível nacional.

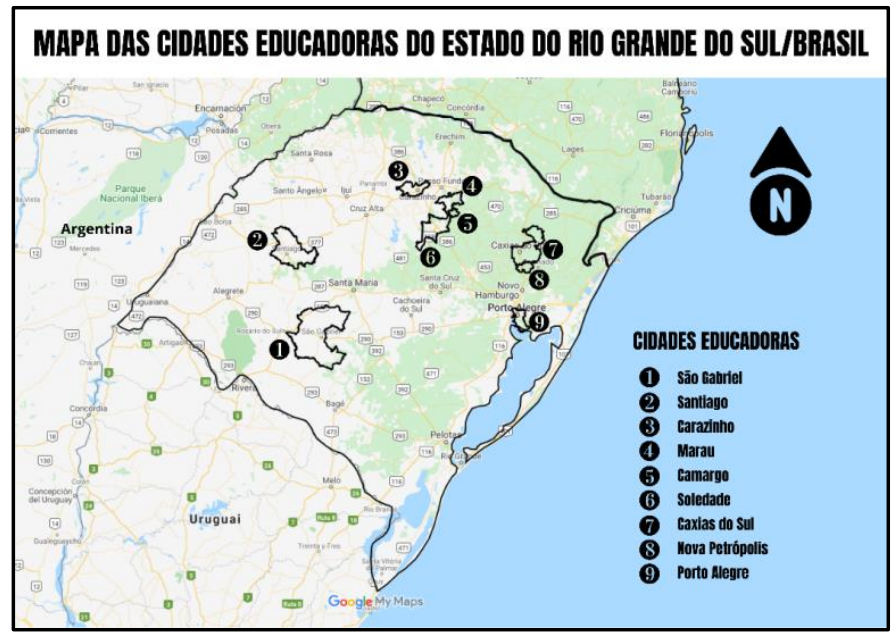

Figura 3 - Mapa das Cidades Educadoras do estado do Rio Grande do Sul/Brasil Fonte: PASTORIO, 2020 (adaptado).

\section{São Gabriel: da proposta inicial aos desdobramentos no território educativo}

$\mathrm{Na}$ construção da São Gabriel como Cidade Educadora, três importantes aspectos/pontos foram considerados: 1 - responsabilidade e investimento do governo local na educação formal; 2 bases históricas e culturais, com bens materiais e imateriais; e, 3 - atividades e eventos executados em âmbito local, pelos diferentes atores sociais.

O Ponto 1 refere-se aos esforços na construção de uma Educação Básica de qualidade, com investimentos e responsabilidades do governo local, na oferta deste serviço público de forma adequada e primando pelos objetivos da educação. Cabe ainda, agregar a aproximação da educação municipal as demais instituições, entidades e empresas locais, pensando uma educação no coletivo e agregando ações e destes agentes sociais, dentro da proposta pedagógica e nas instituições de ensino municipais, além de contribuir para o crescimento desses atores.

No contexto do Ponto 2 são consideradas o contexto das bases históricas e culturais do município, elementos vivos na paisagem e no imaginário do povo local. Retornar ao princípio de 
formação de São Gabriel é aproximar dos alicerces históricos do Brasil, principalmente a disputa e demarcações pela terra (entre Portugal e Espanha, com a presença importante dos negros e indígenas). Para contextualização desse ponto, consideraremos os títulos de "Terra dos Marechais", "Princesa das Coxilhas", "Atenas Rio-Grandense" e "Último Reduto dos Carreteiros" (SÃO GABRIEL, 2017).

Terra dos Marechais devido a ligação com o contexto militar, lugar em que nasceram os Marechais João Propício Menna Barreto, Fábio Patrício de Azambuja, Hermes Rodrigues da Fonseca (Presidente da República, de 1910 a 1914), João Batista Mascarenhas de Moraes (comandante da Força Expedicionária Brasileira na Segunda Guerra Mundial) e o coronel José Plácido de Castro (desbravador que anexou o estado Acre da Bolívia para o Brasil).

Atenas Rio-Grandense devido a presença de importantes e diversos historiadores e escritores, como Alcides Maia (primeiro gaúcho admitido na Academia Brasileira de Letras, eleito em 06 de setembro de 1913), Joaquim Francisco de Assis Brasil (fundador do Partido Liberal, Governador do Rio Grande do Sul, Ministro da Agricultura no Brasil e assinou o Tratado de Petrópolis, na anexação do Acre ao Brasil), Octávio Augusto de Faria (um dos fundadores do Instituto Histórico e Geográfico do Rio Grande do Sul e escreveu o famoso Dicionário Geográfico, Histórico e Estatístico do Rio Grande do Sul) e o Padre Leonel Franca (teólogo fundador da Universidade da PUC do Rio de Janeiro).

Último Reduto dos Carreteiros devido ao uso da carreta de boi (meio de locomoção mais antigo inventado pelo homem) para transportar os produtos cultivados e produzidos das propriedades rurais para ser comercializado na sede urbana, chegando a percorrer até $120 \mathrm{~km}$, entre 5 a 6 dias de viagem (ida e volta), situação ainda existente na unidade territorial.

Princesa das Coxilhas devido ao relevo local, em campos situados em coxilhas de baixa declividade, com várzeas constituindo atrativos naturais, que possibilitam visualizar o horizonte. Nessas coxilhas, que serviu posto para o primeiro povoado do município (Cerro do Batovi) e o segundo povoado, onde encontra-se a sede urbana atual, além do ponto militar estratégico, situado ao centro do estado e no limite dos tratados entre Portugal e Espanha.

O Ponto 3, sobre os aspectos considerados na construção da Cidade Educadora, enaltece as atividades e eventos de propostas educacionais e culturais, desenvolvidos pelos diferentes atores sociais locais. Nesse segmento, podemos citar aquelas ações que são comuns a outras realidades dos municípios gaúchos, como Feira do Livro, Semana da Pátria e Semana da Farroupilha, mas endossado pela Retreta de Bandas, Mostra Pedagógica Municipal, Baile das Mimosas, Carreteada Pedagógica, Semana da Pessoa com Deficiência, Troféu de Atletismo, Festival Estudantil, JINCOP (competições 
esportivas), Expofeira, Encontro de Carros Antigos, Festival de Mini-Vôlei, Circuito de Corrida de Rua, Circuito Estudantil de Corrida de Rua e Estância da Canção Gaúcha, bem como outras atividades de menor porte, que colabora no desenvolvimento educacional de São Gabriel.

Para a continuidade da São Gabriel Cidade Educadora, o conceito está sendo adicionado ao currículo escolar e apresentado aos diferentes atores sociais locais, aproximando-os a compreender os seus objetivos. Quanto aos atores, remete a necessidade de unificar esforços para pensar uma cidade coletiva, aproximação entre repartições e setores, entidades, instituições empresas, públicas e privadas, tornando todos os sujeitos ativos e participativos, sendo responsável pelo seu lugar de atuação.

Pensando a lógica dos Territórios Educativos, o arranjo das políticas deve erradicar a lógica setorializada da gestão pública, "assumindo a intersetorialidade como premissa norteadora das ações e instrumento estratégico de articulação entre instituições, pessoas e saberes" e "fundamentada pela descentralização, a intersetorialidade emerge como oportunidade para que, nos territórios, a gestão de políticas e serviços esteja mais próxima daqueles a quem se destinam, bem como de seus mecanismos de controle social (ACEA, 2018).

$\mathrm{Na}$ construção do currículo escolar, deve anexar os princípios da Carta das Cidades Educadoras no fazer pedagógico escolar, servindo de guia no planejamento, emergindo uma prática docente coletiva e de valorização dos saberes, do tempo e espaço dos estudantes. Como forma de desenvolver o conceito de Cidade Educadora para a comunidade escolar das Escolas Municipais de São Gabriel/RS, a Secretaria Municipal de Educação criou o projeto intitulado de "São Gabriel minha cidade educadora", em maio de 2020. Como as aulas presenciais estão suspensas, em virtude da pandemia do coronavírus (COVID-19), o projeto está contribuindo para nortear os professores no planejamento das atividades pedagógicas não presenciais.

O projeto está estruturado em três fases: Fase 1 é denominada de "O lugar de onde eu falo" (refletir sobre o contexto sociocultural em que vivem, minha casa e minha comunidade), previsto para junho e julho; Fase 2 de "A identidade da minha cidade" (pesquisar e compreender as bases históricas e culturais de São Gabriel/RS), para agosto e setembro; e Fase 3 de "A cidade que me forma e me respeita" (promover e proporcionar a definição de território educativos na constituição da formação integral dos sujeitos), em outubro e novembro.

Nesta perspectiva assinalamos os primeiros passos, no caminho da concretização de uma cidade educadora. Bases importantes (pesquisa, planejamento e socialização) para trilhar a projeção

Revista de Ciências Humanas, Frederico Westphalen - RS, v. 22, n.1, p. 59-74, jan./abr. 2021. Recebido em: 23/05/2021 Aceito em: 02/06/2021 
de um projeto sistemático e progressivo, que consolide uma cidade mais justa, igualitária e participativa para todos.

\section{CONSIDERAÇÕES FINAIS}

Por linhas gerais, o artigo conseguiu apresentar os passos iniciais do município de São Gabriel/RS/Brasil na Associação Internacional de Cidades Educadoras (AICE), demonstrando os esforços e aspectos que foram considerados na construção e consolidação do conceito de Cidade Educadora.

A proposição futura é transformar a cidade como território educativo, que avance para além das bases estruturais da educação formal, materializando como política pública efetiva, de cunho democrático e participativo. Que o governo local se comprometa com o desenvolvimento da cidade, através de meios colaborativos entres todos os atores sociais.

Todas as ações e políticas públicas locais devem ser guiadas pelos três princípios (1 - 0 direito a uma cidade educadora / 2 - 0 compromisso da cidade / 3 - Ao serviço integral das pessoas) da Carta das Cidades Educadoras, que representa o modelo de cidade a ser produzida, assumida quando do ingresso de São Gabriel a AICE, além de serem criadas e estruturas de forma inter e multissetorial, sempre refletindo sobre o impacto e potencialidades educacionais, contribuindo na valorização do território educativo.

A carta preserva e orienta a manutenção de valores fundamentais para a existência humana, fundada na igualdade, democracia, justiça social, sustentabilidade, inclusão, convivência, cooperação, promoção, desenvolvimento e diálogo, entre pessoas, instituições e entidades, no planejamento e execução de ações e reprodução da cidade.

São Gabriel é efetivamente uma Cidade Educadora, que cumpriu os requisitos previstos pela Associação Internacional de Cidades Educadoras e assumiu os princípios da Carta das Cidades Educadoras, tornando-se a $9^{\circ}$ no $\mathrm{RS}, 21^{\circ}$ no Brasil e a $505^{\circ}$ no mundo. Mas além disso, é uma Cidade Educadora por valorizar o seu território educativo (os lugares e os atores sociais) e com o objetivo de promover a transformação social, através da ferramenta da educação.

\section{REFERÊNCIAS}

AICE AMÉRICA LATINA. Espaços Urbanos e Cidades Educadoras. Caderno de Debate $N^{0} 5$. Rosário/Argentina: Sudamerica, 2019. 
AICE. Associação Internacional de Cidades Educadoras. Barcelona/Espanha, AICE, 2020. Disponivel em: <https://www.edcities.org/pt/ >. Acesso em: 24 jun. 2020.

AICE. Da leitura da carta à consolidação de uma cidade educadora - guia metodológico. Barcelona/Espanha: AICE, 2019. Disponível em: < https://www.edcities.org/pt/wpcontent/uploads/sites/46/2020/05/PT_Consolidacio_visualitzacio.pdf>. Acesso em: 24 jun. 2020.

AICE. Carta das Cidades Educadoras. Declaração de Barcelona (1990). Bolonha/ltália: III Congresso Internacional de Cidades Educadoras, 1994. Disponível em: <https://cidadeseducadoras.org.br/wpcontent/uploads/2016/06/carta-cidades-educadoras-barcelona.pdf>. Acesso em: 24 jun. 2020.

AICE. Carta das Cidades Educadoras. Génova/ltália: Congresso Internacional de Cidades Educadoras, 2004. Disponível em: <https://www.edcities.org/pt/wpcontent/uploads/sites/2/2014/03/Charter-in-Portuguese.pdf>. Acesso em: 24 jun. 2020.

AICE. Estatuto da Associação Internacional das Cidades Educadoras. Barcelona/Espanha: AICE, 2004. Disponível em: <https://www.edcities.org/pt/wp-content/uploads/sites/46/2019/01/estatutosPT.pdf >. Acesso em: 24 jun. 2020.

ARROYO, Miguel Gonzalez. Currículo e a Pedagogia de Paulo Freire. In: RIO GRANDE DO SUL. Caderno Pedagógico 2: Semana Pedagógica Paulo Freire. Porto Alegre: SEDUC/CORAG, 2001.

ARROYO, Miguel Gonzalez. Outros Sujeitos, Outras Pedagogias. Petrópolis: Vozes, 2012.

ACEA (ASSOCIAÇÃO CIDADE ESCOLA APRENDIZ). Programa Educação e Território. Território Educativo. São Paulo/SP-Rio de Janeiro/RJ: Associação Cidade Escola Aprendiz, 2018. Disponível em: $<$ https://educacaoeterritorio.org.br/conceito-territorios-educativos/>. Acesso em: 24 jun. 2020.

BRANDÃO, Carlos Rodrigues. A educação popular na escola cidadã. Petrópolis: Vozes, 2002.

BRASIL. Constituição Federal do Brasil. Brasília/DF: Câmara dos Deputados, 1998.

BRASIL. Instituto Brasileiro de Geografia e Estatística. Brasília: IBGE, 2020. Disponível em: <http://www.ibge.gov.br/>. Acesso em: 24 jun. 2020.

BRASIL. Lei de Diretrizes e Bases (LDB). Lei № 9.394/96. Brasília: MEC, 1996.

CAVALCANTI, Lana de S. A Geografia Escolar e a Cidade: ensaios sobre o ensino de geografia para a vida urbana cotidiana. Coleção Magistério: Formação e Trabalho Pedagógico. 3. ed. Campinas/SP: Papirus, 2012.

FAURE, Edgar. Aprender a Ser. Lisboa/Portugal: Livraria Bertrand, 1973.

FREIRE, Paulo. Cartas a Cristina. Rio de Janeiro: Paz e Terra, 1994.

FREIRE, Paulo. Pedagogia do Oprimido. 37. ed. Rio de Janeiro/RJ: Paz e Terra, 2003.

Revista de Ciências Humanas, Frederico Westphalen - RS, v. 22, n.1, p. 59-74, jan./abr. 2021. Recebido em: 23/05/2021 Aceito em: 02/06/2021 
FREIRE, Paulo. Política e Educação. São Paulo/SP: Cortez, 1993.

HARVEY, David. A Justiça Social e a Cidade. São Paulo/SP: Hucitec, 1973.

LACOSTE, Yves. Dicionário de Geografia. Lisboa/Portugal: Teorema, 2005.

LEFEBVRE, Henri. A Revolução Urbana. Belo Horizonte/MG: Ed. UFMG, 2012.

PASTORIO, Eduardo. Nucleação das Escolas do Campo: o caso do município de São Gabriel/RS. Dissertação de Mestrado. Programa de Pós-Graduação em Geografia. Santa Maria: UFSM, 2015.

SANTOS, Milton. Técnica, Espaço, Tempo: globalização e meio técnico-científico informacional. São Paulo/SP: Hucitec, 1994.

SÃO GABRIEL. História. São Gabriel/RS: Prefeitura Municipal, 2017. Disponível em:

<https://www.saogabriel.rs.gov.br/Portal/conheca/historia.html>. Acesso em: 24 jun. 2020.

SÃO GABRIEL. Dispõe sobre a autorização para a adesão à Carta das Cidades Educadoras e ingresso na Associação Internacional das Cidades Educadoras - AICE. Lei Municipal $N^{0}$ 4067/2020. São Gabriel/RS: Câmara de Vereadores, 2019.

TASCHETO, Marcio. Da cidade universitária à cidade como oportunidade pedagógica: extensão, currículo e território. In: AICE AMÉRICA LATINA. Espaços Urbanos e Cidades Educadoras. Caderno de Debate № 5. Rosário/Argentina: Sudamerica, 2019. 